\title{
e-Blood
}

\section{Nomenclature of monocytes and dendritic cells in blood}

\author{
Loems Ziegler-Heitbrock, ${ }^{1,2}$ Petronela Ancuta, ${ }^{3}$ Suzanne Crowe, ${ }^{4}$ Marc Dalod, ${ }^{5-7}$ Veronika Grau, ${ }^{8}$ Derek N. Hart, ${ }^{9}$ \\ Pieter J. M. Leenen, ${ }^{10}$ Yong-Jun Liu, ${ }^{11}$ Gordon MacPherson, ${ }^{12}$ Gwendalyn J. Randolph, ${ }^{13}$ Juergen Scherberich, ${ }^{14}$ \\ Juergen Schmitz, ${ }^{15}$ Ken Shortman, ${ }^{16}$ Silvano Sozzani, ${ }^{17}$ Herbert Strobl, ${ }^{18}$ Marek Zembala, ${ }^{19}{ }^{*}$ Jonathan M. Austyn, ${ }^{20}$ and \\ *Manfred B. Lutz ${ }^{21}$
}

\begin{abstract}
${ }^{1}$ Helmholtz Zentrum München, Gauting, Germany; ${ }^{2}$ Department of Infection, Immunity and Inflammation, University of Leicester, Leicester, United Kingdom; ${ }^{3}$ Université de Montréal, Centre Hospitalier de l'Universite de Montreal (CHUM), and Inserm Unit 743, Montreal, QC; ${ }^{4}$ Macfarlane Burnet Institute for Medical Research, Melbourne, Australia; ${ }^{5}$ Centre d'Immunologie de Marseille-Luminy (CIML), Université de la Méditerranée, Marseille, France; 6 Inserm U631, Marseille, France; ' ${ }^{7}$ entre National de la Recherche Scientifique (CNRS) Unité Mixte de Recherche (UMR) 6102, Marseille, France; ${ }^{8}$ Laboratory of Experimental Surgery, Department of General and Thoracic Surgery, University of Giessen, Giessen, Germany; ${ }^{9}$ Anzac Research Institute, Sydney, Australia; ${ }^{10}$ Department of Immunology, Erasmus University Medical Center, Rotterdam, The Netherlands; ${ }^{11}$ Department of Immunology, University of Texas, M. D. Anderson Cancer Center, Houston, TX; ${ }^{12}$ Sir William Dunn School of Pathology, University of Oxford, Oxford, United Kingdom; ${ }^{13}$ Mount Sinai School of Medicine, New York, NY; ${ }^{14}$ Klinik für Nephrologie und Klinische Immunologie, Municipal Hospital Harlaching, Ludwig-Maximilians-University, Muenchen, Germany; ${ }^{15}$ Department of Research and Development, Miltenyi Biotec, Bergisch Gladbach, Germany; ${ }^{16}$ The Walter and Eliza Hall Institute of Medical Research, Melbourne, Australia; ${ }^{17}$ Department of Biomedical Sciences and Biotechnology, University of Brescia, Brescia, Italy; ${ }^{18}$ Institute of Immunology, Medical University Vienna, Wien, Austria; ${ }^{19}$ Department of Clinical Immunology, Polish-American Institute of Paediatrics, Jagiellonian University Medical College, Krakow, Poland; ${ }^{20}$ Nuffield Department of Surgery, John Radcliffe Hospital, University of Oxford, Oxford, United Kingdom; and ${ }^{21}$ Institute for Virology and Immunobiology, University of Wuerzburg, Wuerzburg, Germany
\end{abstract}

Monocytes and cells of the dendritic cell lineage circulate in blood and eventually migrate into tissue where they further mature and serve various functions, most notably in immune defense. Over recent years these cells have been characterized in detail with the use of cell surface markers and flow cytom- etry, and subpopulations have been described. The present document proposes a nomenclature for these cells and defines 3 types of monocytes (classical, intermediate, and nonclassical monocytes) and 3 types of dendritic cells (plasmacytoid and 2 types of myeloid dendritic cells) in human and in mouse blood. This classification has been approved by the Nomenclature Committee of the International Union of Immunological Societies, and we are convinced that it will facilitate communication among experts and in the wider scientific community. (Blood. 2010;116(16):e74-e80)

\section{Introduction}

The nomenclature of monocytes and dendritic cells (DCs) in blood has become quite confusing because of the use of different antibodies for their identification, and due to the existence of several subpopulations, and to the swapping of nomenclature between species. To resolve this, a group of experts drafted a nomenclature proposal under the auspices of the International Union of Immunological Societies (IUIS) and the World Health Organization. This proposal was discussed at a workshop organized by the Dendritic Cells for Novel Immunotherapies (DCTHERA) European Network of Excellence and the European Macrophage and Dendritic Cell Society in Brescia, Italy, in 2008. After the meeting, the amended proposal was extensively discussed, and finally the nomenclature, presented in this paper, was agreed by the panel as a current consensus, acknowledging that it may well require review in the future.

The nomenclature follows the general rule of giving species and tissue a nonpreemptive name and informative markers. At this stage the nomenclature proposal refers to the steady state; its application to inflammatory conditions has to be done with care, because inflammation may perturb the expression of markers

Submitted February 19, 2010; accepted June 28, 2010. Prepublished online as Blood First Edition paper, July 13, 2010; DOI 10.1182/blood-2010-02-258558.

*J.M.A. and M.B.L. contributed equally to this study. independent of changes in the composition of cell populations. Knowledge about cells in the blood compartment, because of the ready access, is greatest in humans, whereas fewer studies are available for mouse and rat. Because of that, humans take the lead in this nomenclature proposal. We propose herein the terminology classical, intermediate, and nonclassical for the different types of blood monocytes, and for cells of the DC lineage we suggest the terms plasmacytoid and myeloid blood DCs, with 2 distinct types for the latter. These names are combined with informative cellsurface markers.

\section{Monocytes}

Early studies have shown that bone marrow precursors give rise to monocytes in blood, which circulate for a few days before they migrate into tissue where they develop into different types of macrophages. ${ }^{1}$ Cells of this lineage are collectively referred to as mononuclear phagocytes or monocytes/macrophages. They are multifunctional with roles in homeostasis, immune defense, and 
Table 1. Nomenclature of blood monocytes

\begin{tabular}{|c|c|}
\hline Iman & Mouse $^{\star}$ \\
\hline I CD14++ CD16- monocy & Classical Ly6C $\mathrm{C}^{++} \mathrm{CD}$ \\
\hline termediate $\mathrm{CD} 14^{++} \mathrm{CD} 16^{+}$monocytes & Intermediate $\mathrm{Ly}_{6} \mathrm{C}^{++} \mathrm{CD} 43^{++}$monocytes \\
\hline onclassical CD $14^{+} \mathrm{CD} 16^{++}$monocytes & Nonclassical Ly6C $\mathrm{C}^{+} \mathrm{CD} 43^{++}$monocytes \\
\hline \multicolumn{2}{|c|}{$\begin{array}{l}\text { The CD markers given are considered most appropriate at this time. They may be } \\
\text { superseded by superior reagents in the future. The }{ }^{+} \text {denotes an expression level that } \\
\text { is } \sim 10 \text {-fold above the isotype control and }{ }^{++} \text {is } \sim 100 \text {-fold above the isotype control. } \\
\text { *Additional markers have to be used to define the cells under study as monocytes } \\
\text { (see text). }\end{array}$} \\
\hline
\end{tabular}

tissue repair, and they were shown to express an extremely diverse transcriptome. ${ }^{2}$ In humans, monocytes were initially defined on the basis of morphology and cytochemistry (monocyte-specific esterase) and later by flow cytometry that was based on light scatter properties and on cell-surface markers such as CD14. This technology enabled the identification of a CD16 ${ }^{+}$subpopulation, ${ }^{3}$ which is characterized by higher major histocompatibility complex (MHC) class II expression and after stimulation by Toll-like receptor (TLR) ligands by higher tumor necrosis factor (TNF) production. ${ }^{4-6}$ In addition, these cells were shown to expand in inflammatory diseases. ${ }^{7,8}$ The classical $\mathrm{CD} 16^{-}$monocytes and these $\mathrm{CD}_{16}{ }^{+}$cells were shown to share morphology, cytochemistry, and many cell-surface markers. The more recent approach of expression profiling and hierarchical clustering has substantiated the close relationship of the 2 types of cells. ${ }^{9,10}$ In addition, monocytes with an intermediate phenotype between classical and CD $14{ }^{\text {low }} \mathrm{CD} 16^{+}$monocyte subsets have been described. These are found at low frequency, but they have unique features and expand with cytokine treatment and in inflammation. ${ }^{11-17}$

It has been shown that monocytes can differentiate into DCs in vitro and in vivo. ${ }^{18-22}$ Although monocytes, therefore, might be addressed as DC precursors, the panel agreed that these cells still are best called monocytes, because they are not exclusively precursors of DCs but are also the precursors of macrophages.

The use of popular terms such as "inflammatory monocytes," or "proinflammatory monocytes" is not recommended because this leads to confusion as the label inflammatory has been used for different subpopulations in humans and mice. In addition, these terms may prematurely ascribe functional attributes to cells based on ex vivo studies while they largely remain to be functionally characterized in vivo. Earlier, the main monocyte population in humans has been called "classical monocytes,"4 and later it was suggested to label the CD16 ${ }^{+}$cells "nonclassical monocytes." 23 This approach has been adopted for monocytes in the present nomenclature.

\section{Human blood monocytes}

For human blood monocytes a subdivision into 3 subsets, that is, classical, intermediate, and nonclassical, is suggested (Table 1).

Because for the monocyte/macrophage system the term monocyte is reserved for the cells in blood, it was felt that it is not necessary to always use the label blood when referring to monocytes. Classical monocytes are the cells known to hematologists for a century as monocytes on the basis of structure, whereas the somewhat smaller, nonclassical monocytes, which account for only $10 \%$ of all monocytes, were described only 20 years ago. There appears to be a developmental relationship between these cells (from classical by intermediates to nonclassical) in that, during the course of an infection or with macrophage colony-stimulating factor (M-CSF) treatment, there is an increase first of the intermediate cells followed by an increase of the nonclassical CD $14^{+} \mathrm{CD} 16^{++}$ monocytes. ${ }^{13}$ Here, ${ }^{+}$denotes an expression level that is $\sim 10$-fold above the isotype control and ${ }^{++}$is $\sim 100$-fold above the isotype control. With a gradual development from classical to nonclassical monocytes, it may be difficult at times to determine the boundaries between the subpopulations. As with any immunofluorescence analysis, isotype controls are to be used for proper determination of subpopulations.

The CD14 and CD16 markers have proven useful in many studies in the literature, and their use is recommended for determination of subpopulations. For human monocytes CD14 and CD16 antibodies targeting different epitopes are available. For CD14 we suggest the use of antibodies directed against the lipopolysaccharide-binding domain and for CD16 those that bind to the Fc-binding domain. To exclude granulocytes CD66b can be helpful, but intracellular lactoferrin is also a robust marker for exclusions of neutrophils. ${ }^{24}$ For exclusion of natural killer cells CD56 is recommended, and staining for MHC class II expression and for low-level CD4 on monocytes can also be helpful.

CD43, although showing a strong differential staining in mouse monocytes subsets (see "Mouse blood monocytes"), gives only a weak difference for the human subsets and is not recommended for standard staining. CCR2/CD192 staining, however, distinguishes human subsets very clearly, and there is also differential expression in the mouse. ${ }^{25,26} \mathrm{CCR} 2$ may well become a marker for definition of subpopulations in the future, but its usefulness for this purpose still needs further study.

Published evidence for further subsets includes proliferating monocytes and 6-sulfo LacNAc ${ }^{+}$and Fc $\in \mathrm{RI}^{+}$monocytes. ${ }^{27-31}$ Once more information from different research groups is available, these subpopulations can potentially be incorporated in this nomenclature. Taken together, we recommend to subdivide human monocytes into 3 subsets on the basis of the expression of CD14 and the CD16 receptors (Figure 1). The classical monocytes show high $\mathrm{CD} 14$ expression but no $\mathrm{CD} 16\left(\mathrm{CD} 14^{++} \mathrm{CD} 16^{-}\right)$, the intermediate monocytes show a high level of CD14 together with low CD16 $\left(\mathrm{CD} 14^{++} \mathrm{CD} 16^{+}\right)$, and the nonclassical monocytes express a low level of CD14 together with high CD16 $\left(\mathrm{CD} 14^{+} \mathrm{CD} 16^{++}\right.$; Table 1). When the intermediate and the nonclassical monocytes are not separately defined, then we propose to address them collectively as $\mathrm{CD} 16^{+}$monocytes.

\section{Mouse blood monocytes}

For mouse blood monocytes a subdivision into 3 subsets similar to humans is proposed, that is, classical, intermediate, and nonclassical (Table 1).

Markers CD43 and Ly6C have proven to be informative with respect to differential expression. Reagents detecting the Gr-1 epitope, which is present on both Ly6C and Ly6G, are available, but the use of specific anti-Ly6C antibodies is to be preferred. In addition, models that use transgenic mice have been highly informative for definition of monocyte subpopulations such as mice with differential expression of $\mathrm{CX}_{3} \mathrm{CR} 1$-promoter-driven marker genes. ${ }^{26,32,33}$ Such studies on chemokine receptor expression have shown that the classical monocytes in the mouse are $\mathrm{CCR} 2^{\text {high }}$ and $\mathrm{CX}_{3} \mathrm{CR} 1^{\text {low }}$, whereas the nonclassical monocytes are $\mathrm{CCR} 2^{\text {low }}$ and $\mathrm{CX}_{3} \mathrm{CR} 1^{\text {high }}$.

Because none of the markers used for subset definition is monocyte specific, additional markers such as CD11b or CD115 (M-CSF receptor) have been used to define monocytes as such. The M-CSF receptor has been used because it clearly discriminates monocytes from granulocytes. The disadvantage of this marker is that the CD115 protein can be cleaved under 


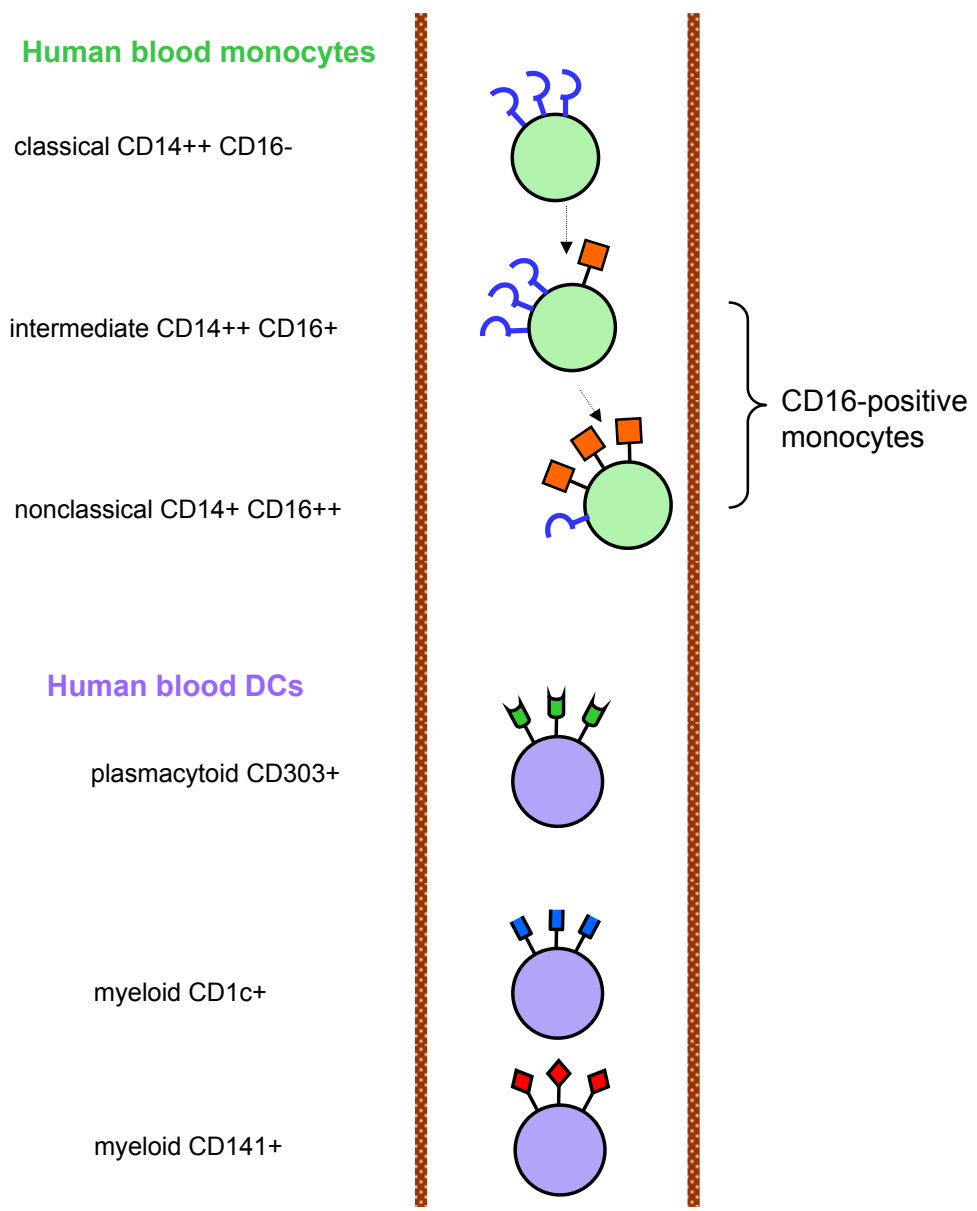

Figure 1. Nomenclature of monocytes and DCs in blood. The 6 types of cells are shown with different symbols, which represent the crucial markers of the respective cells. Blue hook indicates CD14; red square flag, CD16; green flag, CD303; blue flag, CD1c; red diamond flag, CD141. A higher number of a given symbol indicates a higher density of a given receptor. The arrows in the upper portion represent the developmental relationship. This does not necessarily indicate that development is actually occurring in the blood compartment. The location of the nonclassical monocytes closer to the vessel wall is to indicate that these cells preferentially localize to the marginal pool, a concept supported by the intravital microscopic data for the mouse homologue. The 2 types of myeloid DCs are depicted closer to each other because both are closer related to each other compared with the plasmacytoid DCs. conditions of inflammation. This can be obviated with the use of M-CSF-R promoter-driven green fluorescent protein, but, unfortunately, such animals show strong green fluorescent protein expression also in granulocytes. ${ }^{34}$ In addition, although CD14 is expressed by mouse monocytes, the signal is too weak to serve as a monocyte marker in this species. Therefore, a single optimum defining marker for mouse monocytes is still needed.

Cell-depletion studies have shown a developmental relationship between classical and nonclassical monocytes ${ }^{35}$ in that the nonclassical monocytes in mouse blood are more mature and derived from the classical monocytes. Because this relationship is also found in humans, these data support the concept that the nonclassical Ly $6 \mathrm{C}^{+} \mathrm{CD} 43^{++}$monocytes in mouse blood are homologous to human nonclassical $\mathrm{CD} 14^{+} \mathrm{CD} 16^{++}$monocytes. Furthermore, studies on cytokine expression after stimulation with TLR ligands have shown higher levels of TNF protein per cell in the nonclassical monocytes compared with the classical monocytes both in humans and mouse. ${ }^{4,36}$ Similar to humans intermediate cells in the mouse were shown to have unique features. ${ }^{37}$

In addition, in the mouse nonclassical monocytes show lower CD14 and higher CD16 staining compared with the classical monocytes, ${ }^{38}$ further supporting the concept that the nonclassical monocytes in humans and mouse are homologous cell types. Finally, transcriptional profiling of mouse subsets has provided further evidence for the homology of the nonclassical blood monocytes in humans and mouse. ${ }^{38,39}$

Again, it may be difficult to determine the boundaries between the mouse monocyte subpopulations, especially when it comes to the intermediate cells. Unique markers for these intermediate cells are required. Taken together, we suggest a subdivision of mouse monocytes similar to humans on the basis of the expression of Ly6C and CD43. The classical monocytes show high Ly6C expression and low $\mathrm{CD} 43\left(\mathrm{Ly} 6 \mathrm{C}^{++} \mathrm{CD} 43^{+}\right)$, the intermediate monocytes show a high level of Ly6C together with high CD43 $\left(\right.$ Ly6 $\left.\mathrm{C}^{++} \mathrm{CD} 43^{++}\right)$, and the nonclassical monocytes express a low level of Ly6C together with high CD43 $\left(\mathrm{Ly}_{6} \mathrm{C}^{+} \mathrm{CD} 43^{++}\right.$; Table 1).

For rat blood monocytes a few groups have addressed subpopulations. ${ }^{40-42}$ Although there is evidence for heterogeneity, a nomenclature for blood monocytes subsets in the rat is considered premature at this point in time. Note, however, that also in the rat, CD43 is differentially expressed among monocyte subsets, and transfer of $\mathrm{CD} 43^{+}$monocytes gives rise to $\mathrm{CD} 43^{++}$cells in vivo. ${ }^{42}$ This suggests a similar developmental relationship between subsets as has been observed in humans and mouse. However, a definite description of rat monocyte subsets awaits further study with an appropriate set of markers and with functional analyses. In any case, we suggest that the terms "classical" and "nonclassical" might be used in other species besides human and mouse when the appropriate counterparts have been identified.

\section{Blood DCs}

DCs were first identified as a discrete cell type in lymphoid organs in the mouse. ${ }^{43}$ Cells assigned to the DC lineage in blood have been characterized mainly in humans with a few studies available for the mouse and no data for the rat. Again, the human system takes the lead when it comes to nomenclature for cells in blood. The panel 
recognizes the difficulty of defining a DC compared with a monocyte/macrophage because these 2 cell types are closely related, as evidenced by the findings that blood monocytes can differentiate into $\mathrm{DCs}^{18-22}$ and that DCs from human blood can differentiate into macrophages. ${ }^{44}$ In addition, the expression of individual markers such as the commonly used CD11c is not restricted to DCs; $90 \%$ of human monocytes and approximately $40 \%$ of mouse monocytes are $\mathrm{CD} 11 \mathrm{c}^{+}, 35,45$ and alveolar macrophages in the mouse are also CD11 $\mathrm{c}^{+} .{ }^{46} \mathrm{In}$ fact, it is very difficult at present to identify a single marker that can be used to clearly assign a cell to either the monocyte or the DC lineage. When taking an unbiased approach and analyzing the entire transcriptome of the 2 monocyte subsets (classical CD14 ${ }^{++} \mathrm{CD} 16^{-}$and nonclassical $\mathrm{CD} 14^{+} \mathrm{CD} 16^{++}$) compared with 3 types of DCs (HLA-DR ${ }^{+}$ positive cells negative for markers of other leukocyte lineages) in human blood, then hierarchical clustering shows that 3 blood DC populations cluster together and are clearly separated in their expression profile from the 2 monocyte populations. ${ }^{9}$ Therefore, we can group the 3 cells of the DC lineage together and can assign them collectively to the DC lineage.

Still, these blood cells do not have typical characteristics of DCs as seen in tissue. It is apparent that they lack dendrites and also lack markers of mature DCs such as CD83. In addition, in blood they most likely do not present antigen to $\mathrm{T}$ cells, because this would require close cell-cell contacts, which is unlikely to occur under flow conditions. Rather, these DC lineage cells appear to be in transit, and they mature into functional DCs only after entering the tissue.

So far, 3 cell types assigned to the DC lineage have been identified in human blood. Among these the plasmacytoid DC subset might be addressed as being at an immature DC stage rather than a precursor, because they have properties of circulating sentinel cells that, after receiving a maturation signal such as virus contact, can enter the lymph node through high endothelial venules to prime T cells immediately. ${ }^{47}$ By contrast, the $\mathrm{CD} \mathrm{c}^{+}$and CD $141^{+}$DC lineage cells show features of both DC precursors ("preDCs") and of immature DCs. Similar to immature DCs they have the potential to act as sentinel cells because in vitro they secrete cytokines when activated, they effectively stimulate $\mathrm{T}$ cells, and they rapidly mature in response to TLR agonists. ${ }^{48,49}$ However, the $\mathrm{CD} 1 \mathrm{c}^{+}$and $\mathrm{CD} 141^{+} \mathrm{DC}$ lineage cells fail to mature in response to TNF, and they express early myeloid markers such as CD33 at high levels, features that would suggest a classification as DC precursors. ${ }^{48,50}$ A nomenclature that reflects such distinct maturational stages of the DCs in blood would be confusing. Therefore, the panel agreed on the term "blood DCs" for the entire collection of cells. This terminology goes along with the connotation that a blood DC is not a mature cell of this lineage.

\section{Human DC lineage cells}

For human DC lineage cells in blood a subdivision into 3 subsets is suggested, that is, plasmacytoid DCs and 2 types of myeloid DCs.

Plasmacytoid DCs in tissues were originally described as T-associated plasma cells, plasmacytoid T cells, or plasmacytoid monocytes. ${ }^{51-53}$ When these cells were first isolated from human tonsils, they were shown to have the ability to differentiate into mature DCs in culture with interleukin-3. ${ }^{54}$ In parallel research a subpopulation of human blood cells, enriched in cells expressing MHC class II and CD4, was found to have the capacity to produce high levels of interferon $\alpha$ (IFN- $\alpha$ ) in response to viruses, and these cells were named natural type 1 IFN-producing cells. ${ }^{55,56}$ In crucial experiments it was shown that these IFN-producing cells are, in
Table 2. Nomenclature of blood dendritic cells

\begin{tabular}{ll}
\hline Human & \multicolumn{1}{c}{ Mouse } \\
\hline Plasmacytoid $\mathrm{CD} 303^{+}$blood DCs & Plasmacytoid blood DCs \\
Myeloid CD1c ${ }^{+}$blood DCs & Myeloid blood DCs \\
Myeloid CD $141^{+}$blood DCs & Myeloid blood DCs \\
\hline
\end{tabular}

The CD markers given are considered most appropriate at this time. They may be superseded by superior reagents in the future. CD303 is the official name for the commercial antibody BDCA-2, CD1c is BDCA-1, and CD141 is BDCA-3.

fact, the plasmacytoid DCs. ${ }^{47,57}$ The CD68 marker can discriminate the plasmacytoid DCs from the 2 types of myeloid DCs, but this requires combination with additional markers because CD68 is also strongly expressed on monocytes. ${ }^{58}$ While CD123 expression is only incrementally higher on plasmacytoid DCs compared with monocytes, CD303 is a marker with good signal-to-noise ratio for the plasmacytoid DCs. ${ }^{59}$

Both the $\mathrm{CD}_{1} \mathrm{c}^{+}$and $\mathrm{CD} 141^{+}$myeloid blood DCs express myeloid markers CD13 and CD33, suggesting their direct derivation from the myeloid lineage. Although earlier studies relied on exclusion of all other lineages of leukocytes combined with high-level MHC class II expression to study these blood DCs, the CD1c and CD141markers available now only require exclusion of a few cell types that coexpress these markers.

For proper identification of the $\mathrm{CD}_{1} \mathrm{c}^{+} \mathrm{DCs}$ in blood, $\mathrm{CD} 19^{+} \mathrm{CD} 20^{+} \mathrm{B}$ cells need to be excluded, because the latter cells also show strong expression of the CD1c molecule. A fraction of the CD1 $\mathrm{c}^{+}$blood DCs expresses low-level CD14. ${ }^{60}$ No comparative data are available on the $\mathrm{CD} 14^{+}$and $\mathrm{CD} 14^{-}$subsets of the $\mathrm{CD} 1 \mathrm{c}^{+}$cells at this time. In support of their uniqueness functional studies on $\mathrm{CD} 1 \mathrm{c}^{+}$cells have shown a specific pattern of chemokine production in these cells. ${ }^{61}$

The CD $141^{+}$DCs represent a very minor subset of blood leukocytes. Costaining with CD14 is recommended to exclude low-level signals from monocytes. These CLEC9A ${ }^{+} \mathrm{CD} 141^{+}$cells (but not $\mathrm{CD} 1 \mathrm{c}^{+}$blood DCs) are also major producers of IFN- $\beta$ and cross-present antigen for CD8 class 1-restricted cytotoxic $\mathrm{T}$ lymphocyte responses in response to TLR-3/CD283 ligation. These and their other properties suggest that they are homologous to the mouse $\mathrm{CD} 8^{+}$DC subset. ${ }^{62-65}$

It is recommended that the $\mathrm{CD} 1 \mathrm{c}^{+}$and $\mathrm{CD} 141^{+}$blood DCs are defined separately and are not addressed as one population of myeloid blood DCs.

Taken together, we recommend to define human blood DCs as MHC class II-positive, lineage marker-negative cells and to subdivide them into 3 subtypes. These are the plasmacytoid $\mathrm{CD} 03^{+} \mathrm{DCs}$, the myeloid CD1c ${ }^{+}$DCs, and the myeloid CD $141^{+}$ DCs (Table 2).

\section{Mouse DC lineage cells}

For mouse DC lineage cells in blood little information is available. Still, a subdivision into plasmacytoid and myeloid DCs appears to emerge.

For plasmacytoid DCs blood cells with a high capacity to produce IFN- $\alpha$ in response to cytosine-phosphate-guanosine stimulation have been defined as CD11 $\mathrm{c}^{\text {low }}, \mathrm{CD} 11 \mathrm{~b}^{-}, \mathrm{CD}_{45 \mathrm{RA}} \mathrm{A}^{\text {high }}$ cells. ${ }^{66}$ Anti-bone marrow stromal cell Ag 2 (BST2) antibodies have been described to stain mouse plasmacytoid DCs in spleen, and staining of mouse blood cells has shown a strong signal for BST2 ${ }^{67,68}$ However, expression of the BST2 antigen on plasma cells under steady state conditions and on many other cells after induction by type I IFN needs to be considered. 
Looking at myeloid DCs the $\mathrm{CD} 11 \mathrm{c}^{+} \mathrm{CD} 11 \mathrm{~b}^{+} \mathrm{CD} 45 \mathrm{RA}^{-}$ cells identified in mouse blood share features with the splenic $\mathrm{CD}^{-}$DC subset, ${ }^{66}$ and they may be homologous to human $\mathrm{CD} \mathrm{c}^{+}$myeloid blood DCs. ${ }^{9}$

The CLEC9A ${ }^{+}$DC in mouse blood also stain for CD24 and may thus be representative for the $\mathrm{CD}^{+}$splenic DC subset. Because anti-CLEC9A also strongly stains the human blood $\mathrm{CD}_{141}{ }^{+}$cells ${ }^{65}$ and because human CD $141^{+}$blood DCs and mouse $\mathrm{CD}^{+}$spleen DCs share specific transcriptional signatures, ${ }^{9}$ the $\mathrm{CLEC} \mathrm{A}^{+}$mouse blood DCs are potential homologues of the human $\mathrm{CD}_{141}{ }^{+} \mathrm{CLEC} \mathrm{A}^{+}$myeloid blood DCs. Taken together, it is clear that there are plasmacytoid and 2 types of myeloid DCs in mouse blood, but the optimum markers await to be defined. Therefore, the nomenclature proposal for the mouse does not give identifying markers at this time (Table 2). For the time being, it is suggested to define the myeloid subsets with the compilation of markers, for example, mouse myeloid CD11 ${ }^{+} \mathrm{CD} 11 \mathrm{~b}^{+} \mathrm{CD}_{45 \mathrm{RA}^{-}}$ blood DCs.

Differentiation of bone marrow plasmacytoid DCs into $\mathrm{CD}_{11 \mathrm{~b}}{ }^{+} \mathrm{CD} 45 \mathrm{RA}^{-}$myeloid DCs shows the close relationship of the plasmacytoid and myeloid DC types. ${ }^{69}$ In addition, transcriptional profiling and hierarchical clustering of mouse spleen DCs have shown that the mouse plasmacytoid DCs and the $\mathrm{CD}^{+}$and $\mathrm{CD}^{-}$DCs cluster together in a manner similar to what has been shown for human blood DCs. In addition, the same analysis showed coclustering of the human and mouse plasmacytoid DCs. ${ }^{9}$ For further consolidation of the mouse blood DCs it will be important to analyze expression of orthologues of informative human cell-surface markers. In addition, transcriptional profiling of purified mouse blood DCs is required for comparison to humans.

Taken together, we recommend to define mouse blood DCs similar to humans and to subdivide them into 3 subtypes. These are the plasmacytoid DCs and 2 types of myeloid DCs. Because specific markers for these cells in mouse blood are still to be identified, they currently have to be defined with the use of combinations of cell-surface markers.

For rat DC lineage cells in blood no data are currently available. It is expected that homologues of the 3 types of human blood DCs can be defined in the future with the use of reagents that target the same or novel DC-specific molecules.

\section{Technical aspects}

The analysis of monocytes and blood DCs requires special attention because the frequency of some of these cells can be very low. Therefore, contamination of the population of interest by unwanted events needs to be excluded. For flow cytometric analysis, we, therefore, suggest to use unprocessed blood, exclusion of dead cells, gating on CD45, and no gating on scatter whenever possible and to use reagents with high signal to noise ratio. In addition, high numbers of total events need to be acquired to obtain sufficient numbers of specific events for a meaningful analysis.

When reporting on monocytes and blood DCs in lectures and publications, we recommend that flow cytometric plots of representative examples are given initially in the paper or as supplementary data in online publications, and these need to define the cells based on isotype controls to show the signal compared with noise. For optimum assessment the isotype control and the specific antibody need to be derived from the same manufacturing process with the same fluorochrome-to-protein ratio. For multicolor flow cytometric analysis the "fluorescence minus one" principle needs to be followed, that is, only one antibody is exchanged for an isotype control at a time. ${ }^{70}$

\section{Conclusion}

The present nomenclature proposal avoids the use of functional terms such as "proinflammatory" for monocyte and blood DC subpopulations. Such terms may be stimulating and make integration of the cells into mechanistic concepts easier. However, such a nomenclature can lead our thinking and our research into wrong directions such that we disregard anti-inflammatory properties of a cell dubbed proinflammatory. Therefore, a neutral nomenclature is proposed for monocytes and blood DCs.

For monocyte subpopulations the classical versus intermediate and nonclassical nomenclature allows for other markers to be used for the 3 subsets in the future. When new markers are used for human monocyte subsets then their validity needs to be shown with reference to the CD14 and CD16 dot plots, and a combination with these established markers is always recommended. The same applies to Ly6C and CD43 dot plots in the mouse. In addition, the nomenclature proposal for blood DCs is open to additional subpopulations.

At this stage the nomenclature applies to humans and mouse. It may be applicable directly to nonhuman primates, but for the bovine, porcine, and rat systems much more experimental work is needed. We expect that the comprehensive analysis of gene expression (transcriptome, proteome, metabolome, etc) in subpopulations of blood monocytes and of blood DCs will refine this nomenclature and will help in consolidating homologues in the different species.

\section{Acknowledgments}

We thank Laurence Boumsell (Nomenclature Chair of IUIS http://www.iuisonline.org/pages/nomenclature.htm) for her expert advice and guidance throughout the process.

This work was supported by the DC-THERA, Network of Excellence, EC Contract No. LSHB-2004-512074 (www.dc-thera.org).

L.Z.-H. is chairing the IUIS nomenclature subcommittee on blood monocytes and dendritic cells.

\section{Authorship}

Contribution: All authors contributed to the discussion of the nomenclature, were involved in writing, and agreed with the proposal presented herein.

Conflict-of-interest disclosure: J. Schmitz is employed by Miltenyi Biotec, a company that sells reagents to identify monocyte and dendritic cell subsets. D.N.H. is a consultant for TransBio Ltd. P.J.M.L.'s institution has received royalties for commercially available anti-mouse monocyte antibodies from AbD Serotec, BMA Biomedicals, Santa Cruz Biotechnology, and Hycult Biotechnology. The remaining authors declare no competing financial interests.

Correspondence: Loems Ziegler-Heitbrock, Helmholtz Zentrum München, Robert-Koch-Allee 29, 82131 Gauting, Germany; e-mail: ziegler-heitbrock@helmholtz-muenchen.de. 


\section{References}

1. van Furth R, Cohn ZA. The origin and kinetics of mononuclear phagocytes. J Exp Med. 1968(3);128:415-35.

2. Wells CA, Chalk AM, Forrest A, et al. Alternate transcription of the Toll-like receptor signaling cascade. Genome Biol. 2006;7(2):R10.

3. Passlick B, Flieger D, Ziegler-Heitbrock HW. Identification and characterization of a novel monocyte subpopulation in human peripheral blood. Blood. 1989;74(7):2527-2534.

4. Belge KU, Dayyani F, Horelt A, et al. The proinflammatory CD14+CD16+DR++ monocytes are a major source of TNF. J Immunol. 2002;168(7):3536-3542.

5. Szaflarska A, Baj-Krzyworzeka M, Siedlar M, et al. Antitumor response of CD14+/CD16+ monocyte subpopulation. Exp Hematol. 2004; 32(8):748-755.

6. Serbina NV, Cherny M, Shi C, et al. Distinct responses of human monocyte subsets to Aspergillus. J Immunol. 2009;183(4):2678-2687.

7. Fingerle G, Pforte A, Passlick B, Blumenstein M, Ströbel M, Ziegler-Heitbrock HW. The novel subset of CD14+/CD16+ blood monocytes is expanded in sepsis patients. Blood. 1993;82(10): 3170-3176.

8. Nockher WA, Scherberich JE. Expanded CD14+ CD16 + monocyte subpopulation in patients with acute and chronic infections undergoing hemodialysis. Infect Immun. 1998;66(6):2782-2790.

9. Robbins SH, Walzer T, Dembele D, et al. Novel insights into the relationships between dendritic cell subsets in human and mouse revealed by genome-wide expression profiling. Genome Biol. 2008;9(1):R17.

10. Ancuta P, Liu KY, Misra V, et al. Transcriptional profiling reveals developmental relationship and distinct biological functions of CD16+ and CD16- monocyte subsets. BMC Genomics. 2009;10:403.

11. Ancuta $P$, Rao R, Moses A, et al. Fractalkine preferentially mediates arrest and migration of CD16+ monocytes. J Exp Med. 2003;197(12): 1701-1707.

12. Skrzeczynska-Moncznik J, Bzowska M, Loseke S, Grage-Griebenow E, Zembala M, Pryjma J. Peripheral blood CD14high CD16+ monocytes are main producers of IL-10. Scand. J Immunol. 2008;67(2):152-159.

13. Weiner LM, Li W, Holmes M, et al. Phase I trial of recombinant macrophage colony-stimulating factor and recombinant gamma-interferon: toxicity, monocytosis, and clinical effects. Cancer Res. 1994;54(15):4084-4090

14. Grage-Griebenow E, Zawatzky R, Kahlert $H$, Brade L, Flad H, Ernst M. Identification of a novel dendritic cell-like subset of CD64(+)/CD16(+) blood monocytes. Eur J Immunol. 2001;31(1): 48-56.

15. Ellery PJ, Tippett E, Chiu YL, et al. The CD16+ monocyte subset is more permissive to infection and preferentially harbors HIV-1 in vivo. J Immunol. 2007;178(10):6581-6589.

16. Moniuszko M, Bodzenta-Lukaszyk A, Kowal K, Lenczewska D, Dabrowska M. Enhanced frequencies of CD14++CD16+, but not CD14+CD16+, peripheral blood monocytes in severe asthmatic patients. Clin Immunol. 2009;130(3):338-346

17. Heron M, Grutters JC, van Velzen-Blad H Veltkamp M, Claessen AM, van den Bosch JM. Increased expression of CD16, CD69, and very late antigen-1 on blood monocytes in active sarcoidosis. Chest. 2008;134(5):1001-1008.

18. Peters JH, Ruppert J, Gieseler RK, Najar HM, $\mathrm{Xu} \mathrm{H}$. Differentiation of human monocytes into CD14 negative accessory cells: do dendritic cells derive from the monocytic lineage? Pathobiology 1991;59(3):122-126.

19. Romani N, Gruner S, Brang D, et al. Proliferating dendritic cell progenitors in human blood. J Exp Med. 1994;180(1):83-93.

20. Sallusto F, Lanzavecchia A. Efficient presentation of soluble antigen by cultured human dendritic cells is maintained by granulocyte/macrophage colony-stimulating factor plus interleukin 4 and downregulated by tumor necrosis factor alpha. J Exp Med. 1994;179(4):1109-1118.

21. Randolph GJ, Inaba K, Robbiani DF, Steinman RM, Muller WA. Differentiation of phagocytic monocytes into lymph node dendritic cells in vivo. Immunity. 1999;11(6):753-761.

22. Varol C, Landsman L, Fogg DK, et al. Monocytes give rise to mucosal, but not splenic, conventional dendritic cells. J Exp Med. 2007;204(1):171-180.

23. Strauss-Ayali D, Conrad SM, Mosser DM. Monocyte subpopulations and their differentiation patterns during infection. J Leukoc Biol. 2007;82(2): 244-252.

24. Knapp W, Strobl H, Majdic O. Flow cytometric analysis of cell-surface and intracellular antigens in leukemia diagnosis. Cytometry. 1994;18(4): 187-198.

25. Weber C, Belge KU, von Hundelshausen P, et al Differential chemokine receptor expression and function in human monocyte subpopulations. J Leukoc Biol. 2000;67(5):699-704.

26. Palframan RT, Jung S, Cheng G, et al. Inflammatory chemokine transport and presentation in HEV: a remote control mechanism for monocyte recruitment to lymph nodes in inflamed tissues. $J$ Exp Med. 2001;194(9):1361-1373.

27. Clanchy FI, Holloway AC, Lari R, Cameron PU, Hamilton JA. Detection and properties of the human proliferative monocyte subpopulation. J Leukoc Biol. 2006;79(4):757-766.

28. Tjew SL, Brown KL, Kannagi R, Johnson P. Expression of $\mathrm{N}$-acetylglucosamine 6-O-sulfotransferases (GIcNAc6STs)- 1 and -4 in human monocytes: GlcNAc6ST-1 is implicated in the generation of the 6-sulfo $\mathrm{N}$-acetyllactosamine/Lewis $\mathrm{x}$ epitope on CD44 and is induced by TNF-alpha. Glycobiology. 2005;15(7):7C-13C.

29. de Baey A, Mende I, Riethmueller G, Baeuerle PA. Phenotype and function of human dendritic cells derived from M-DC8(+) monocytes. Eur J Immunol. 2001;31(6):1646-1655.

30. Maurer D, Fiebiger E, Reininger B, et al. Expression of functional high affinity immunoglobulin $E$ receptors (Fc epsilon $\mathrm{RI}$ ) on monocytes of atopic individuals. J Exp Med. 1994;179(2): 745-750.

31. von Bubnoff $D$, Fimmers $\mathrm{R}$, Bogdanow $\mathrm{M}$, Matz $\mathrm{H}$, Koch S, Bieber T. Asymptomatic atopy is associated with increased indoleamine 2,3-dioxygenase activity and interleukin-10 production during seasonal allergen exposure. Clin Exp Allergy. 2004;34(7):1056-1063.

32. Geissmann F, Jung S, Littman DR. Blood monocytes consist of two principal subsets with distinc migratory properties. Immunity. 2003;19(1): 71-82

33. Auffray C, Fogg D, Garfa M, et al. Monitoring of blood vessels and tissues by a population of monocytes with patrolling behavior. Science. 2007;317(5833):666-670.

34. Sasmono RT, Ehrnsperger A, Cronau SL, et al. Mouse neutrophilic granulocytes express mRNA encoding the macrophage colony-stimulating factor receptor (CSF-1R) as well as many other macrophage-specific transcripts and can transdifferentiate into macrophages in vitro in response to CSF-1. J Leukoc Biol. 2007;82(1):111-123.

35. Sunderkotter $\mathrm{C}$, Nikolic T, Dillon MJ, et al. Sub- populations of mouse blood monocytes differ in maturation stage and inflammatory response. $J$ Immunol. 2004;172(7):4410-4417.

36. Burke B, Ahmad R, Staples KJ, et al. Increased TNF expression in CD43 $(++)$ murine blood monocytes. Immunol Lett. 2008;118(2):142-147.

37. Qu C, Edwards EW, Tacke F, et al. Role of CCR8 and other chemokine pathways in the migration of monocyte-derived dendritic cells to lymph nodes. J Exp Med. 2004;200(10):1231-1241.

38. Ingersoll MA, Spanbroek R, Lottaz C, et al. Comparison of gene expression profiles between human and mouse monocyte subsets. Blood. 2010; 115(3):e10-e19.

39. Randolph GJ, Jakubzick C, Qu C. Antigen presentation by monocytes and monocyte-derived cells. Curr Opin Immunol. 2008;20(1):52-60.

40. Ahuja V, Miller SE, Howell DN. Identification of two subpopulations of rat monocytes expressing disparate molecular forms and quantities of CD43. Cell Immunol. 1995;163(1):59-69.

41. Scriba A, Schneider M, Grau V, van der Meide PH, Steiniger B. Rat monocytes up-regulate NKR-P1A and down-modulate CD4 and CD43 during activation in vivo: monocyte subpopulations in normal and IFN-gamma-treated rats. J Leukoc Biol. 1997;62(6) 741-752.

42. Yrlid U, Jenkins CD, MacPherson GG. Relationships between distinct blood monocyte subsets and migrating intestinal lymph dendritic cells in vivo under steady-state conditions. J Immunol. 2006;176(7):4155-4162.

43. Steinman RM, Cohn ZA. Identification of a nove cell type in peripheral lymphoid organs of mice. I. Morphology, quantitation, tissue distribution. J Exp Med. 1973;137(5):1142-1162.

44. Robinson SP, Patterson S, English N, Davies D, Knight SC, Reid CD. Human peripheral blood contains two distinct lineages of dendritic cells. Eur J Immunol. 1999;29(9):2769-2778.

45. Hogg N, Takacs L, Palmer DG, Selvendran Y, Allen C. The p150,95 molecule is a marker of human mononuclear phagocytes: comparison with expression of class II molecules. Eur J Immunol. 1986;16(3):240-248.

46. van Rijt LS, Jung S, Kleinjan A, et al. In vivo depletion of lung CD11c + dendritic cells during allergen challenge abrogates the characteristic features of asthma. J Exp Med. 2005;201(6): 981-991.

47. Cella M, Jarrossay D, Facchetti F, et al. Plasmacytoid monocytes migrate to inflamed lymph nodes and produce large amounts of type I interferon. Nat Med. 1999;5(8):919-923.

48. Piccioli D, Tavarini S, Borgogni E, et al. Functional specialization of human circulating CD16 and CD1c myeloid dendritic-cell subsets. Blood. 2007;109(12):5371-5379.

49. Kohrgruber N, Halanek N, Groger M, et al Survival, maturation, and function of CD11c- and $\mathrm{CD} 11 \mathrm{c}+$ peripheral blood dendritic cells are differentially regulated by cytokines. $\mathrm{J}$ Immunol. 1999;163(6):3250-3259.

50. MacDonald KP, Munster DJ, Clark GJ, Dzionek A, Schmitz J, Hart DN. Characterization of human blood dendritic cell subsets. Blood. 2002;100(13): 4512-4520.

51. Lennert K, Remmele W. Karyometrische Untersuchungen an Lymphknotenzellen des Menschen. Acta Haematol. 1958;19(2):99-113.

52. Feller AC, Lennert K, Stein H, Bruhn HD, Wuthe $\mathrm{HH}$. Immunohistology and aetiology of histiocytic necrotizing lymphadenitis: Report of three instructive cases. Histopathology. 1983;7(6): 825-839.

53. Facchetti F, de Wolf-Peeters C, Mason DY, Pulford K, van den Oord JJ, Desmet VJ. Plasmacytoid T cells. Immunohistochemical evidence for 
From www.bloodjournal.org at Helmholtz Zentrum Muenchen Zentralbibliothek on October 25, 2010. For

their monocyte/macrophage origin. Am J Pathol. 1988;133(1):15-21.

54. Grouard G, Rissoan M-C, Filgueira L, Durand I, Banchereau J, Liu Y-J. The enigmatic plasmacytoid T cells develop into dendritic cells with interleukin (IL)-3 and CD40-ligand. J Exp Med. 1997; 185(6):1101-1112.

55. Perussia B, Fanning V, Trinchieri G. A leukocyte subset bearing HLA-DR antigens is responsible for in vitro alpha interferon production in response to viruses. Nat Immun Cell Growth Regul. 1985; 4(3):120-137.

56. Fitzgerald-Bocarsly P, Feldman M, Mendelsohn M, Curl S, Lopez C. Human mononuclear cells which produce interferon-alpha during NK(HSV-FS) assays are HLA-DR positive cells distinct from cytolytic natural killer effectors. J Leukoc Biol. 1988;43(4):323-334.

57. Siegal FP, Kadowaki N, Shodell M, et al. The nature of the principal type 1 interferon-producing cells in human blood. Science. 1999;284(5421): 1835-1837.

58. Strobl H, Scheinecker C, Riedl E, et al. Identification of CD68+ lin- peripheral blood cells with dendritic precursor characteristics. J Immunol. 1998; 161(2):740-748.

59. Dzionek A, Fuchs A, Schmidt P, et al. BDCA-2,
BDCA-3, and BDCA-4: three markers for distinct subsets of dendritic cells in human peripheral blood. J Immunol. 2000;165(11):6037-6046.

60. Thomas R, Lipsky PE. Human peripheral blood dendritic cell subsets. Isolation and characterization of precursor and mature antigen-presenting cells. J Immunol. 1994;153(9):4016-4028.

61. Penna G, Vulcano M, Roncari A, Facchetti F Sozzani S, Adorini L. Cutting edge: differential chemokine production by myeloid and plasmacytoid dendritic cells. J Immunol. 2002;169(12): 6673-6676.

62. Jongbloed SL, Kassianos AJ, McDonald KJ, et al. Human CD141 + (BDCA-3) + dendritic cells represent a unique myeloid dendritic cell subset that cross-presents necrotic cell antigens. J Exp Med. 2010;207(6):1247-1260.

63. Crozat K, Guiton R, Contreras V, et al. The XC chemokine receptor 1 is a conserved selective marker of mammalian cells homologous to mouse CD8alpha+ dendritic cells. J Exp Med. 2010;207(6):1283-1292.

64. Robbins SH, Walzer T, Dembélé D, et al. Novel insights into the relationships between dendritic cell subsets in human and mouse revealed by genome-wide expression profiling. Genome Biol. 2008;9(1):R17.

65. Caminschi I, Proietto Al, Ahmet F, et al. The den- dritic cell subtype-restricted C-type lectin Clec9A is a target for vaccine enhancement. Blood. 2008; 112(8):3264-3273

66. O'Keeffe M, Hochrein H, Vremec D, et al. Dendritic cell precursor populations of mouse blood: identification of the murine homologues of human blood plasmacytoid pre-DC2 and CD11c+ DC1 precursors. Blood. 2003;101(4):1453-1459.

67. Asselin-Paturel C, Brizard G, Pin JJ, Briere F, Trinchieri G. Mouse strain differences in plasmacytoid dendritic cell frequency and function revealed by a novel monoclonal antibody. J Immunol. 2003;171(12):6466-6477.

68. Blasius AL, Giurisato E, Cella M, Schreiber RD, Shaw AS, Colonna M. Bone marrow stromal cell antigen 2 is a specific marker of type I IFN-producing cells in the naive mouse, but a promiscuous cell surface antigen following IFN stimulation. J Immunol. 2006;177(5):3260-3265.

69. Zuniga El, McGavern DB, Pruneda-Paz JL, Teng C, Oldstone MB. Bone marrow plasmacytoid dendritic cells can differentiate into myeloid dendritic cells upon virus infection. Nat Immunol. 2004;5(12):1227-1234.

70. Roederer M. Compensation is not dependent on signal intensity or on number of parameters. Cytometry. 2001;46(6):357-359. 